\title{
Evaluate the effectiveness of the UV/persulfate process to remove catechol from solution aqueous
}

\author{
Kamarehie B. ${ }^{1}$, Jafari A. ${ }^{1}$, Shams Khoramabadi G. ${ }^{1}$, Mansouri Bidkani M. ${ }^{2}$, Ghadepoori M. ${ }^{1,3 *}$, Karami M.A. ${ }^{1}$ and Ghaderpoory A. ${ }^{4}$ \\ ${ }^{1}$ Department of Environmental Health Engineering, School of Health and Nutrition, Lorestan University of Medical Sciences, \\ Khorramabad, Iran \\ ${ }^{2}$ Student Research Committee, Lorestan University of Medical Sciences, Khorramabad, Iran \\ ${ }^{3}$ Nutrition Health Research Center, Lorestan University of Medical Sciences, Khorramabad, Iran \\ ${ }^{4}$ Student Research Committee, Department of Environmental Health Engineering, Shahid Beheshti University of Medical Sciences, \\ Tehran, Iran \\ Received: 03/04/2020, Accepted: 02/01/2021, Available online: 22/02/2021 \\ *to whom all correspondence should be addressed: e-mail: mghaderpoori@gmail.com \\ https://doi.org/10.30955/gnj.003322
}

\section{Graphical abstract}

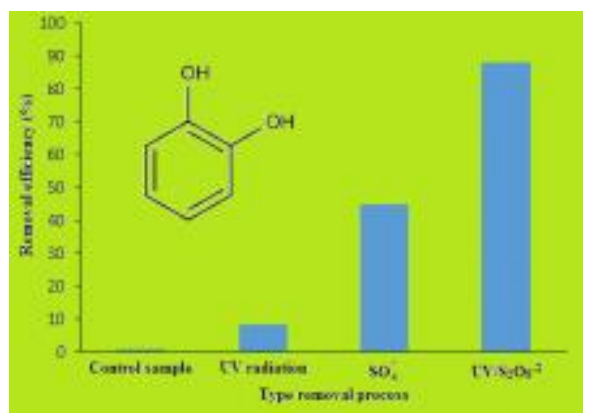

\begin{abstract}
Catechol is used as an antioxidant, fungicide, and polymerization inhibitors in a variety of industries such as petrochemical. Catechol must be removed from effluents before it enters to environment. This study aimed to investigate combined UV radiation and persulfate process in removal of catechol from aqueous solutions. All experiments were performed in a batch reactor. Data analysis were done with Design of Experiment (DoE) software. The effects of various variables such as $\mathrm{pH}$, initial persulfate concentration, and initial Catechol concentration were investigated. The findings indicated with increases in persulfate concentration and decrease in catechol concentrations, the removal efficiency increased. Acidic $\mathrm{pH}$ and $\mathrm{UV}$ radiation were the leading factors in removal of catechol. The optimum $\mathrm{pH}$, persulfate concentration, and catechol concentration were obtained 7, $0.04 \mathrm{M}$, and $100 \mathrm{mg} \mathrm{l}^{-1}$, respectively. More removes of catechol was achieved in optimum conditions within contact time of $60 \mathrm{~min}$. The synergic effects of UV and persulfate radical were about $88 \%$. Approximately $60 \%$ of catechol was mineralized within contact time of $60 \mathrm{~min}$. Persulfate radicals resulting from $\mathrm{UV} / \mathrm{S}_{2} \mathrm{O}_{8}{ }^{2-}$ were the main effective oxidants in removal and mineralization of catechol. Owing to high removal efficiency of persulfate
\end{abstract}

compounds which are, also, abundant and inexpensive, these can be applied in removal of persistent organic pollutants from aqueous solutions.

Keywords: Persulfate radical, catechol, UV radiation, advanced oxidation.

\section{Introduction}

Catechol, one of the derivation of phenol, is colorless and has a phenol-like smell (Moussavi et al., 2014). Catechol has a phenolic ring which bonds to two Hydroxyl $\left(\mathrm{OH}^{\circ}\right)$ functional groups (Bayram et al., 2009; Liu et al., 2014). Catechol can enter into our environment from various sources such as photographic developer, paper and pulp, textile, pharmacy, insecticides, paint, engine lubricants, oil refinery, petrochemical lubricating oils, polymerization inhibitors and pharmaceutical (Lofrano et al., 2009). It is applied as an antioxidant, fungicide, and polymerization inhibitors in various industries. The catechol concentration in the effluents of different industries is range less than one to $1000 \mathrm{mg} \mathrm{l}^{-1}$ (Bayram et al., 2009; Liu et al., 2014). The catechol concentration is typically low in environment, but the effluents of industrials processes may contain catechol concentrations ranging from one to $1000 \mathrm{mg} / \mathrm{l}$. It is synthetically produced by hydroxylation of phenol using Hydrogen peroxide $\left(\mathrm{H}_{2} \mathrm{O}_{2}\right)$ or created by Hydrolysis of 2chlorophenol with alkali metals hydroxides (Moussavi et al., 2014; Shakir et al., 2008). Catechol similar to other phenol derivations has toxicity and can cause environmental and health concerns such as irritation of eye, skin, pulmonary, liver dysfunction, DNA destruction, and neurological diseases. Catechol easily adsorbed to digestive tract, and it can result in hemolysis and acute tubular necrosis (Gunawardana et al., 2011; Hamad et al., 2011; Zhao et al., 2010). Catechol is more toxic and hazardous to human, environment, and microorganisms compared to phenol (Sun et al., 2010). To date, a variety of physicochemical methods have been investigated for the removal of catechol compounds from the aqueous 
solutions, including biological process, air oxidation, wet oxidation by $\mathrm{H}_{2} \mathrm{O}_{2}$, and adsorption (Haidari et al., 2016; Kamali and Ghaziaskar, 2010). The important drawbacks of these technologies include failure to complete degradation of contaminants, contaminant transmission from a phase to another, and production by-products as well (Azarpira et al., 2019; Hasanpour and Hatami, 2020a; Sun et al., 2010; Zhao et al., 2010). In recent decades, advanced oxidation processes (AOPs) such as Fenton, $\mathrm{H}_{2} \mathrm{O}_{2} / \mathrm{O}_{3}, \mathrm{H}_{2} \mathrm{O}_{2} / \mathrm{UV}$, and $\mathrm{O}_{3} / \mathrm{UV}$ have been widely using as high-efficiency processes for removal of resistant (persistent) pollutants from soil, water, and wastewater (Ghaderpoori and Dehghani, 2016; Haidari et al., 2016; Hasanpour and Hatami, 2020b; Kamali and Ghaziaskar, 2010; Shukla et al., 2010c). The major purposes of these techniques are producing high-oxidation radical, including $\mathrm{OH}^{\circ}, \mathrm{O}^{\circ}$, and the sulfate radical, which rapidly oxidize and remove resistant substances to biodegradation (Antoniou et al., 2010). For these reasons, a great number of studies have been done to remove phenol derivations with different radicals (Kamali and Ghaziaskar, 2010; Kamarehie et al., 2018; Kamarehie et al., 2020; Rokhina et al., 2010; Sun et al., 2010). These radicals provide situations to react with persistent substances and increase pollutants degradation (Boukari et al., 2011). Persulfate has an oxidizing potential equal to $2.01 \mathrm{~V}$ (Gayathri et al., 2010). An effective mechanism of persulfate is generating the sulfate radical and $\mathrm{OH}^{\circ}$ radicals and using them for degradation of organic matters. However, more studies have concluded that degradation rate of organic matter, in room temperature, is very low by persulfate radicals. Therefore, accelerating process for activation (increases in concentration of radicals) is needed (Shukla et al., 2010a). Persulfate can be activated by various method such as increasing temperature, adding intermediate metals $\left(\mathrm{Me}^{2+}\right.$ ) and UV radiation (Astereki et al., 2016; Liang et al., 2006). Physical and chemical activations of persulfate are shown as follows (Karimi et al., 2013; Shukla et al., 2010b):

$$
\begin{aligned}
& \mathrm{S}_{2} \mathrm{O}_{8}^{-2}+\text { heat or } \mathrm{UV} \rightarrow 2 \mathrm{SO}_{4}{ }^{\circ} \text { ) } \\
& \mathrm{Me}^{\mathrm{n+}} \rightarrow \mathrm{SO}_{4}{ }^{\circ-}+\mathrm{Me}^{(\mathrm{n}+1)}+\mathrm{SO}_{4}{ }^{-2}+\mathrm{S}_{2} \mathrm{O}_{8}^{-2} \\
& \mathrm{~S}_{2} \mathrm{O}_{8}^{-2}+\mathrm{Fe}^{+2} \rightarrow \mathrm{SO}_{4}{ }^{\circ}+\mathrm{Fe}^{+3}+\mathrm{SO}_{4}^{-2}
\end{aligned}
$$

The studies have shown that $\mathrm{UV} / \mathrm{S}_{2} \mathrm{O}_{8}{ }^{-2}$ is an effective process to remove persistent organic pollutants (Lin et al., 2011; Salari et al., 2008). A number of researchers have applied this method to remove POPs and obtained similar results. Delavaran Shiraz et al. study showed that persulfate activated by UV and ferrous ions was an effective process in removing catechol (Fang and Shang, 2012; Lin et al., 2011; Lin et al., 2013). Yoon et al. study showed that $\mathrm{UV} / \mathrm{S}_{2} \mathrm{O}_{8}{ }^{-2}$ was very effective in removing bisphenol compared to UV- $\mathrm{H}_{2} \mathrm{O}_{2}$ was an effective process in removing catechol (Yoon et al., 2012). The advantages of the process include low cost, high stability and solubility, storage and easy transfer (Fang and Shang, 2012; Gao et al., 2012). The response surface methodology is good procedure to study the relationship between independent and dependent variables (Massoudinejad et al., 2018;
Yazdanbakhsh et al., 2018). In response surface methodology category, central composite design that is appropriate for fitting second order polynomial equations has been frequently discussed for optimizing several research problems. To design experiments, Design of Experiments Software (DOE) and Central Composite Design (CCD) was applied. In the study, five coded levels $(+\alpha,+1,0$, -1 , and $-\alpha$ ) factorial experimental design was used to optimize the reaction conditions. The aim of present study was to evaluate the effectiveness of the UV/ $\mathrm{S}_{2} \mathrm{O}_{8}{ }^{-2}$ process to remove Catechol from solution aqueous.

\section{Methods}

\subsection{Chemicals and instruments}

Catechol $\left(\mathrm{C}_{6} \mathrm{H}_{6} \mathrm{O}\right.$, white to brown feathery crystal, phenolic odor), $\mathrm{NaOH}, \mathrm{H}_{2} \mathrm{SO}_{4}$, were purchased from Merck Company, Germany. Digital pH meter model BP300 and spectrometer UV/VIS (DR-5000) were used to measure $\mathrm{pH}$ and contaminant concentrations, respectively. Samples $\mathrm{pH}$ were adjusted by adding a few drops of $\mathrm{NaOH}$ and $\mathrm{H}_{2} \mathrm{SO}_{4}$ (1N).

\subsubsection{Design of Experiments (DoE)}

To determine removal efficiency of catechol by $\mathrm{UV} / \mathrm{S}_{2} \mathrm{O}_{8}{ }^{2-}$, initial catechol concentrations (100-500 $\left.\mathrm{mg} \mathrm{l}^{-1}\right), \mathrm{pH}(3-11)$, and persulfate radicals (0.01-0.05 $\mathrm{M}$ ) were considered as dependent variables. Removal efficiency of catechol was dependent variables. The constant UV radiation throughout study was $30 \mathrm{~W}$. The number of experiment were determined 20 run (central point $=20$ run and not center point=14 run. Optimum time for experiment was determined $60 \mathrm{~min}$ after pre-test. The samples were exposed to UV for $60 \mathrm{~min}$, and then the samples were detected. After experiments, the coefficient of the polynomial model were calculated to equation 1 (Eq. 1) (Massoudinejad et al., 2016)

$$
Y(\%)=a_{0}+\sum_{i=1}^{n} a_{i i} X_{i}^{2}+\sum_{i=1}^{n-1} \sum_{j=2}^{n} a_{i j} X_{i} X_{j}+e
$$

Where, $i$ and $j$ are linear and quadratic coefficients, respectively. $a_{0}, a_{i}, a_{i i}$, and $a_{i j}$ are constant, linear, interaction, and quadratic coefficients, respectively. The removal efficiency of Catechol was calculated according to Eq. 2 (Massoudinejad et al., 2016):

$$
R, \%=\frac{\left(C_{0}-C_{t}\right)}{C_{0}}
$$

Where, $C_{\mathrm{o}}$ and $C_{\mathrm{t}}$ represent the initial and final concentration of catechol $\left(\mathrm{mg} \mathrm{L}^{-1}\right)$, respectively. To measure Chemical Oxygen Demand (COD), volumetric method (titration) was applied. All experiments were performed based on standard method for examination of water and wastewater (Eaton AD et al., 2005). First, A 100 $\mathrm{mg} \mathrm{L}^{-1}$ of stock solution was prepared with catechol (purity $98 \%)$. Then, the calibration curve were drawn in different catechol concentrations $\left(2,10,50,100,150\right.$, and $200 \mathrm{mg} \mathrm{L}^{-}$ $\left.{ }^{1}\right)$. After that, residual concentration of catechol were determined by High-Performance Liquid Chromatography (HPLC) (UV detector, wavelength $=275 \mathrm{~nm}$, the column = 
$100-5 \mathrm{C} 18 ; 4.6 \mathrm{~mm} \times 250 \mathrm{~mm}, 5 \mu \mathrm{m}$, temperature $=23^{\circ} \mathrm{C}$, Mobile phase $=$ a mixture of methanol and water 44:55) (Yoon et al., 2012). The experimental runs of CCD show at Table 1. In this work, a $1000 \mathrm{~mL}$ Plexiglas reactor was applied to experiments. Five ultraviolet (UV) tubes 6W, low pressure (PHILIPS), also were used as UV radiation sources. The experiments were performed in a batch reactor, as shown in Figure 1.

Table 1. The runs for removal process of catechol by UV/ $\mathrm{S}_{2} \mathrm{O}_{8}^{-2}$

\begin{tabular}{cccccc}
\hline Run & Catechol conc. $\left(\mathbf{m g ~ L}^{-1}\right)$ & $\mathbf{p H}$ & Persulfate $\left(\mathbf{m g ~ L}^{-1}\right)$ & Removal efficiency (\%) & Predicted value (\%) \\
\hline 1 & 300 & 7 & 0.03 & 94.97 & 94.55 \\
\hline 2 & 300 & 3 & 0.03 & 92.88 & 94.55 \\
\hline 3 & 420 & 5 & 0.02 & 68.28 & 69.64 \\
\hline 4 & 180 & 9 & 0.04 & 700 & 99.88 \\
\hline 5 & 500 & 7 & 0.03 & 71.22 & 71.82 \\
\hline 6 & 300 & 7 & 0.01 & 90.54 & 94.05 \\
\hline 7 & 300 & 7 & 0.03 & 100 & 94.55 \\
\hline 8 & 180 & 5 & 0.4 & 100 & 97.98 \\
\hline 9 & 180 & 5 & 0.02 & 95 & 97.68 \\
\hline 10 & 180 & 9 & 0.02 & 99.86 & 69.55 \\
\hline 11 & 300 & 7 & 0.03 & 94.5 & 94.55 \\
\hline 12 & 420 & 9 & 0.02 & 94.19 & 90.72 \\
\hline 13 & 300 & 7 & 0.03 & 87.19 & 90.72 \\
\hline 14 & 420 & 5 & 0.04 & 89 & 94.55 \\
\hline 15 & 420 & 9 & 0.04 & 95.2 & 96.32 \\
\hline 16 & 300 & 7 & 0.03 & 98.6 & 102.82 \\
\hline 17 & 300 & 7 & 0.05 & 99.85 & 94.55 \\
\hline 18 & 100 & 7 & 0.03 & 95 & 94.55 \\
\hline 19 & 300 & 7 & 0.03 & 99 & \\
\hline 20 & 300 & 11 & 0.03 & & \\
\hline
\end{tabular}

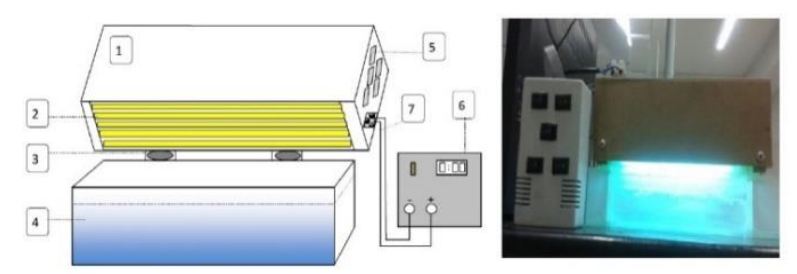

Figure 1. A view of the pilot used for $\mathrm{UV} / \mathrm{S}_{2} \mathrm{O}_{8}{ }^{-2}$

[1-Wooden removable cap, 2-UV lamps, 3-Hinge, 4-Glass reactor with aluminum cover, 5-Switching keys, 6-Power source, 7 Current cables]

\section{Results and discussion}

\subsection{Statistical analysis and model fitting}

The results of present study showed that the catechol removal by UV/ $\mathrm{S}_{2} \mathrm{O}_{8}{ }^{-2}$ was fitted to polynomial models. Also, Analysis of variance (ANOVA) indicated that the selected model has a capability to estimate (predict) process ( $P$-value $<0.05)$. The model F-value of $61.13 \mathrm{implied}$ the model was significant. There was only a $0.01 \%$ chance that a model F-value this large could occur due to noise. Values of prob>F less than 0.05 indicated model terms were significant. In this case $\mathrm{C}, \mathrm{BC}, \mathrm{B}^{2}, \mathrm{C}^{2}$ were significant model terms. Values greater than 0.1 indicated the model terms were not significant. If there were many insignificant model terms (not counting those required to support hierarchy), model reduction may improve your model. The lack of fit (LoF) of F-value of 2.74 implied the lack of fit was not significant relative to the pure error. There was a $13.98 \%$ chance that a LoF of F-value this large could occur due to noise. Non-significant LoF was good. The correlation coefficient, modified correlation, and predicted correlation were in order $0.99,0.97$, and 0.81 , respectively. The predicted $\mathrm{R}$-squared, $\mathrm{R}^{2}$, of 0.86 was in reasonable agreement with the adjustment R-squared of 0.94 . Adequate precision measures the signal to noise $(\mathrm{S} / \mathrm{N})$ ratio. A ratio greater than four is desirable. In this study, $\mathrm{S} / \mathrm{N}$ ratio of 23.015 indicated an adequate signal. This model can be used to navigate the design space. It show the selected model was of high accuracy. The removal efficiency of this study were found to have range $68 \%$ to $100 \%$. The DoE software works based on multivariable linear regression model, the outputs are discussed as following Eq. 3:

$$
\begin{aligned}
R, \% & =89.81+(4.82 * B)-(21.35 * C)+(11.13 * B * C) \\
& -\left(2.56 * B^{2}\right)-\left(13.95 * C^{2}\right)
\end{aligned}
$$

Where, $B$ and $C$ are catechol concentration and the sulfate radical concentration, respectively. The optimum $\mathrm{pH}$, persulfate concentration, and catechol concentration were obtained 7, $0.04 \mathrm{M}$, and $100 \mathrm{mg} \mathrm{L}^{-1}$, respectively. Finally, data validation was performed with the tests: I. normal probability plot of the studentized residuals to check for normality of residuals, II. studentized residuals versus predicted values to check for constant error, III. externally studentized residuals to look for outliers, i.e., influential values. And IV. Box-Cox plot for power transformations.

\subsection{Optimization and model validation}

In DoE software, the optimization of variables is performed in three methods: numerical, graphical, and point 
prediction. This study was to optimize with the use of numerical methods. To obtain the optimal condition for catechol removal and for maximum desirability. catechol concentration, persulfate concentration, initial $\mathrm{pH}$, and contact time were set minimum, minimum, in the range and, in the range, respectively. The best local maximum was found to be at the $\mathrm{pH} 7$, catechol concentration of $181.08 \mathrm{mg} \mathrm{L}^{-1}$, persulfate concentration of $0.04 \mathrm{M}$, contact time of $60 \mathrm{~min}$. Removal efficiency of catechol in the optimal conditions obtained 90 percent, and desirability of one.

\subsection{The effects of $\mathrm{SO}_{4}{ }^{\circ}$ concentration on the removal efficiency of $U \mathrm{~V}-\mathrm{S}_{2} \mathrm{O}_{8}{ }^{-2}$}

The study findings showed that an increase in the sulfate radical concentration can effect on removal efficiency of catechol. Increasing in concentration of oxidant leads to increases in the sulfate radical concentration, which result in promotion of reaction and catechol degradation. Types and concentrations of oxidants are important factors in AOPs. Persulfate $\left(\mathrm{S}_{2} \mathrm{O}_{8}{ }^{2-}\right)$, a two-electron oxidant, produces $\mathrm{SO}_{4}{ }^{\circ}$ with higher redox potential compared to $\mathrm{O}_{3}$ and $\mathrm{OH}^{\circ}$. These radicals can break down organic pollutants (Karimi et al., 2013). In degradation of organic matter, first, the sulfate radical is activated through physical and chemical reaction with UV radiation. Then, the intermediate products such as the sulfate radical are produced (Azbar et al., 2004). The sulfate radicals can mineralize organic matters and produce $\mathrm{CO}_{2}, \mathrm{H}_{2} \mathrm{O}$, and acidic organics. It not only can attack directly to organic matters and degrade them, but also is capable of indirectly reacting to $\mathrm{H}_{2} \mathrm{O}$ and $\mathrm{OH}^{\circ}$, which are two main factors in degradation of organic matters. The polynomial model showed that there as significant relationship between the sulfate radical and removal efficiency of catechol (P-value<0.02). Removal efficiency of catechol in different concentrations of $\mathrm{SO}_{4}{ }^{\circ}$ are illustrated in Figure 2. As can be seen, increases in the sulfate radical concentrations can significantly effect on removal efficiency, so that increases in the sulfate radical concentration from 0.04 to $0.08 \mathrm{M}$ has removal efficiency approximately $18 \%$. The increasing in the removal efficiency of catechol along with increase in concentration of $\mathrm{OH}^{\circ}$ and the sulfate radicals is justifiable (Azbar et al., 2004; Rasoulifard et al., 2012). Yegane et al. achieved the highest removal efficiency in concentration $0.04 \mathrm{mM} \mathrm{L}^{-1}$ of the sulfate radical (Esrafili et al., 2016; Khataee, 2009; Olmez-Hanci and Arslan-Alaton, 2013; Wang and Liang, 2014). Persulfate concentrations can increase the sulfate radical to a specified range, which subsequently result in increases of degradation rate and removal efficiency. The results agreement to Shaing et al. called dye degradation using microwave process and persulfate (Astereki et al., 2016).

\subsection{The effects of initial catechol concentrations on the removal efficiency}

In most studies related to organic matters oxidation, increasing in pollutant concentration have been along with reduction in removal efficiency (Massoudinejad et al., 2020). The study results showed that initial concentrations can significantly effect on removal efficiency. Other similar studies, removal efficiency decreased by increasing catechol concentrations. When the concentrations of persulfate radical and the sulfate radical were constant, but the catechol concentrations are increasing, removal efficiency decreased. Therefore, there were not sufficient available the sulfate radical for degradation. As well, high concentrations of catechol avoid UV radiation to permeate to depth of solution and decreased the persulfate radicals. As a result, the rate of catechol degradation decreased (Lee et al., 2009; Olmez-Hanci and Arslan-Alaton, 2013; Shiying et al., 2009). The results obtained the polynomial model showed that there was significant correlation between initial catechol concentration and the removal efficiency (P-value $<0.001)$. The results of the effects of initial catechol concentrations on removal efficiency are shown in Figure 3. By increasing the initial catechol concentration from 181.08 to 418.92 , the removal rate decreased by approximately $45 \%$. The results showed that adsorption is not appropriate for the removal of higher concentrations of $110 \mathrm{mg} \mathrm{L}^{-1}$ (Lofrano et al., 2009). The results of this study were consistent with other studies (Rasoulifard et al., 2012; Zarrabi et al., 2013).

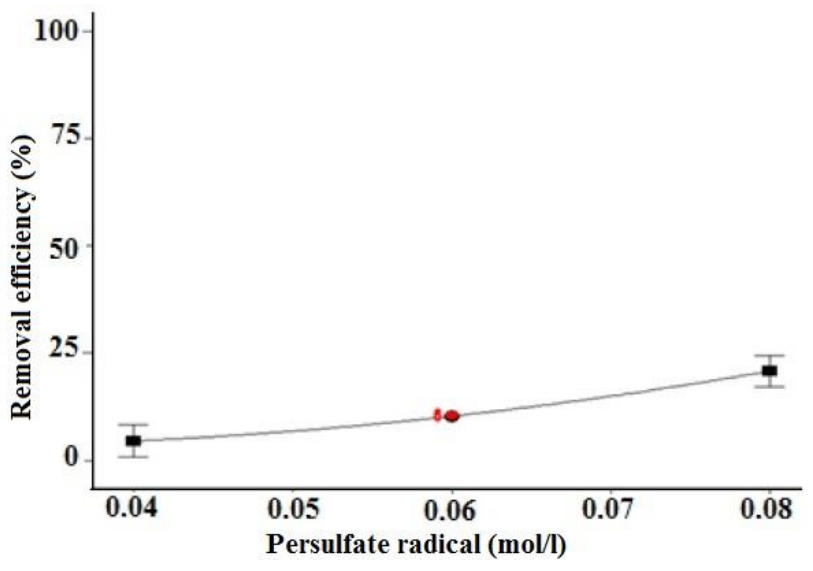

Figure 2. The effects of $\mathrm{SO}_{4}{ }^{\circ}$ on removal efficiency $[\mathrm{pH}=(3-11)$, $\mathrm{UV}$ radiation $=30 \mathrm{~W}$, persulfate concentration $(0.0-2.1 \mathrm{M})$, Catechol concentrations (100- $500 \mathrm{mg} \mathrm{L}^{-1}$ ), and contact time: 60 $\min ]$

\subsection{The effects of $\mathrm{pH}$ on the removal efficiency}

$\mathrm{pH}$ is very effective factor in generation of the sulfate radical and $\mathrm{OH}^{\circ}$ radicals However, most studies emphasize that $\mathrm{pH}$ has important effects on removal efficiency (Alinejad et al., 2019; Kamarehie et al., 2019; Olmez-Hanci and Arslan-Alaton, 2013; Moussavi et al., 2014). For this reason, solution $\mathrm{pH}$ was considered as an important factor in the present study. The results showed $\mathrm{pH}$ can impact on the removal efficiency. The polynomial model indicated that the effect of initial $\mathrm{pH}$ of solutions was not significant ( $\mathrm{P}$-value $<0.46)$. Figure 4 shows the effects of $\mathrm{pH}$ on the removal efficiency of catechol. The best $\mathrm{pH}$ to remove the catechol was neutral conditions. The removal efficiency of catechol was reduced by almost $20 \%$ at acidic and alkaline $\mathrm{pH}$. In a neutral $\mathrm{pH}$, the highest persulfate radicals may be produced, which the increase in radical concentration could have a positive impact on removal efficiency. The 
study results of Yegane et.al on removal of diethyl phthalate with $\mathrm{UV} / \mathrm{S}_{2} \mathrm{O}_{8}{ }^{-2}$ showed that the optimum $\mathrm{pH}$ for high removal efficiency was 11 (Esrafili et al., 2016). Solution $\mathrm{pH}$ in alkaline range were more appropriate than acidic (Guo et al., 2014; Lin et al., 2011; Rasoulifard et al., 2012).

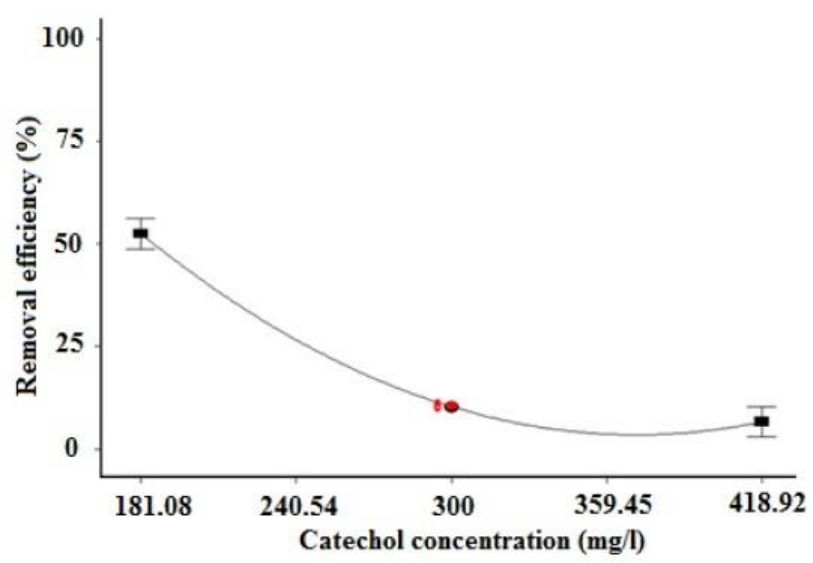

Figure 3. The effects of initial catechol concentrations on efficiency $[\mathrm{pH}=(3-11), \mathrm{UV}$ radiation $=30 \mathrm{~W}$, Persulfate concentrations (0.0-2.1 M), catechol concentrations (100- 500 $\left.\mathrm{mg} \mathrm{L}^{-1}\right)$, and Time: $60 \mathrm{~min}$ ]

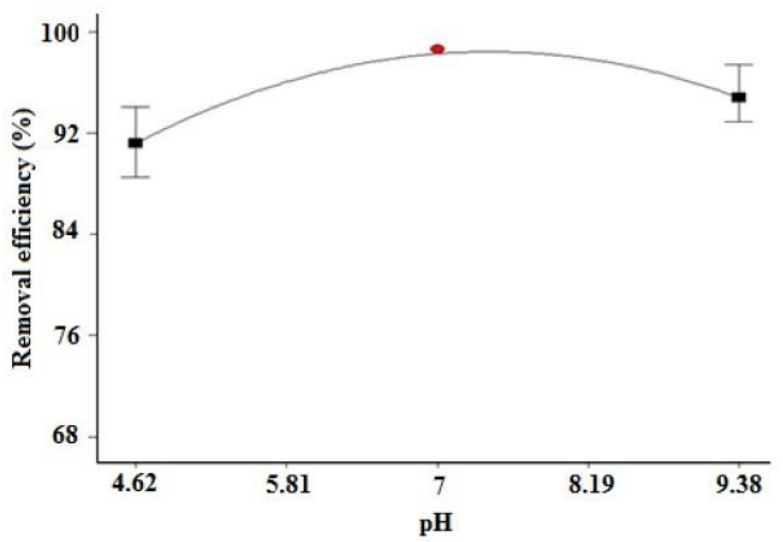

Figure 4. The effects of initial $\mathrm{pH}$ on removal efficiency of catechol $\mathrm{pH}=(3-11), \mathrm{UV}$ radiation $=30 \mathrm{~W}$, Persulfate concentrations (0.0-2.1 M), catechol concentrations (100- 500 $\left.\mathrm{mg} \mathrm{L}^{-1}\right)$, and Time: $\left.60 \mathrm{~min}\right]$

3.6. The interaction effects of $\mathrm{pH}$ and $\mathrm{SO}_{4}{ }^{\circ}$ on the removal efficiency

As can be seen in Figure 5, the findings showed that there were significant relationship between the interaction effects of $\mathrm{pH}$ and the sulfate radical on the removal efficiency of catechol. The most removal efficiency of catechol was observed at neutral. At a constant $\mathrm{pH}$ with increasing concentrations of sulfate radicals, the removal efficiency of Catechol increased. persulfate radical is an oxidizing agent and by increasing the concentration the rate of decomposition increased (Esrafili et al., 2016). The stability of persulfate in aqueous solutions are more than $\mathrm{OH}^{\circ}$ (Shokouhi et al., 2010). Another reaction which occurred in in alkaline $\mathrm{pH}$ is reaction between persulfate and $\mathrm{OH}^{\circ}$ radicals (Eq. 4) (Xu et al., 2012). This reaction significantly decreases the removal efficiency, because of the lack of radicals under this conditions.

$$
\mathrm{SO}_{4}^{\circ}+\mathrm{OH}^{\circ} \rightarrow \mathrm{H}^{+}+\mathrm{SO}_{4}^{-2}
$$

The results were agreement with the results of Piternal et.al (Chu et al., 2015). Also, Seymohamaddi et.al obtained the similar results in removal of 2,4-dichlorophenol by ultrasound -activated persulfate in aqueous solutions (Shukla et al., 2010c). Cho et.al concluded removal efficiency in acidic $\mathrm{pH}$ was much better than alkaline (Peternel et al., 2010).

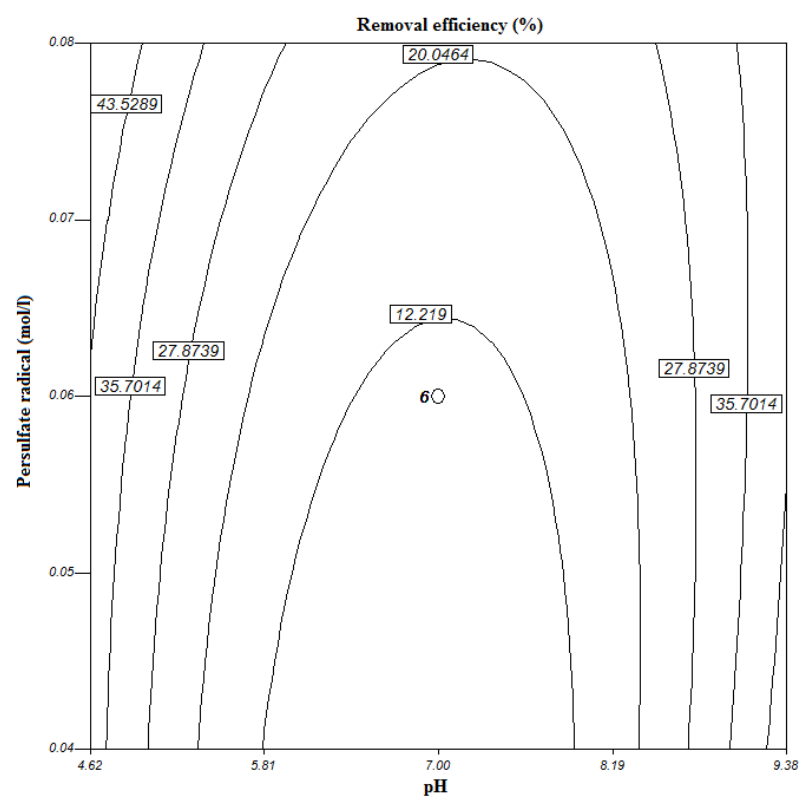

Figure 5. The simultaneous effects of $\mathrm{pH}$ and initial catechol concentrations on removal efficiency $[\mathrm{pH}=(3-11)$, UV radiation= $30 \mathrm{~W}$, Persulfate concentrations $(0.0-2.1 \mathrm{M})$, Catechol (100- $\left.500 \mathrm{mg} \mathrm{L}^{-1}\right)$, and Time: $60 \mathrm{~min}$ ]

3.7. The interaction effects of $\mathrm{SO}_{4}{ }^{\circ}$ and catechol concentrations on removal efficiency

As can be seen in Figure 6, the results showed that there was a significant relationship between the sulfate radical and catechol concentrations on removal efficiency of catechol ( $\left.P_{\text {valve }}<0.05\right)$. At constant concentration of persulfate radical, catechol removal efficiency decreases with increasing of catechol concentration.

\subsection{The effect of contact time on removal efficiency}

Kinetic studies are used to predict the rate of degradation and its mechanisms (Golmohammadi et al., 2016). Figure 7 shows the results of kinetic studies of catechol degradation with $\mathrm{UV} / \mathrm{S}_{2} \mathrm{O}_{8}{ }^{-2}$ processes in optimum coditions. The results showed that the rate of pollutant removal was fitted to pseudo- the pseudo-first order model $\left(R^{2}=0.98 \%\right)$. 


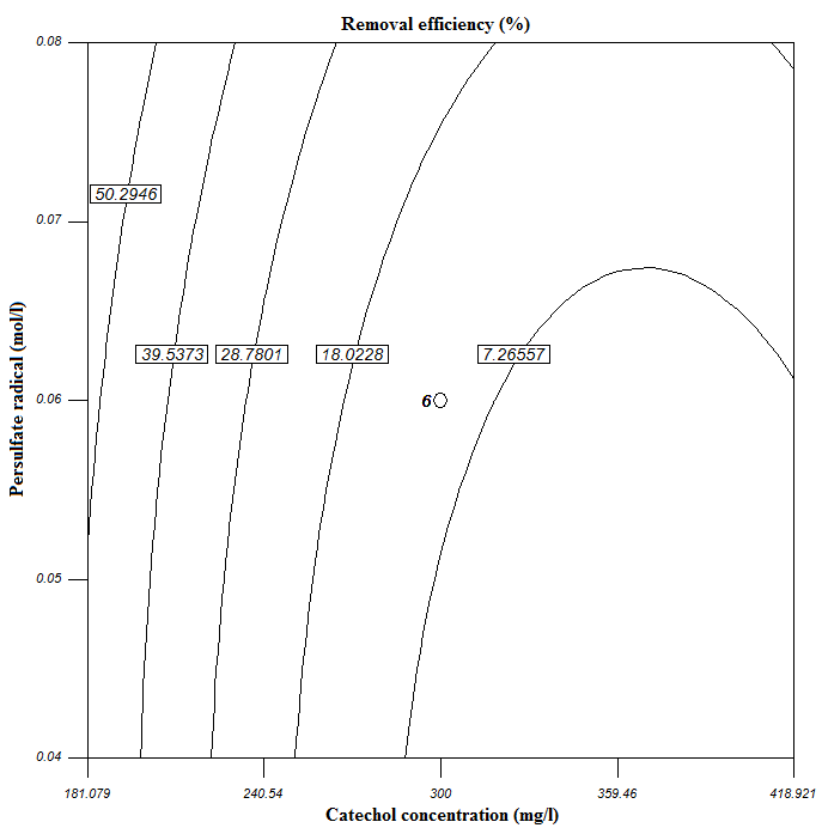

Figure 6. The simultaneous effects of $\mathrm{SO}_{4}{ }^{\circ}$ and catechol concentrations on removal efficiency $[\mathrm{pH}=(3-11)$, UV radiation=

$30 \mathrm{~W}$, persulfate concentration (0.0-2.1) M, catechol concentrations (100-500 $\left.\mathrm{mg} \mathrm{L}^{-1}\right)$, and contact time $\left.=60 \mathrm{~min}\right]$.

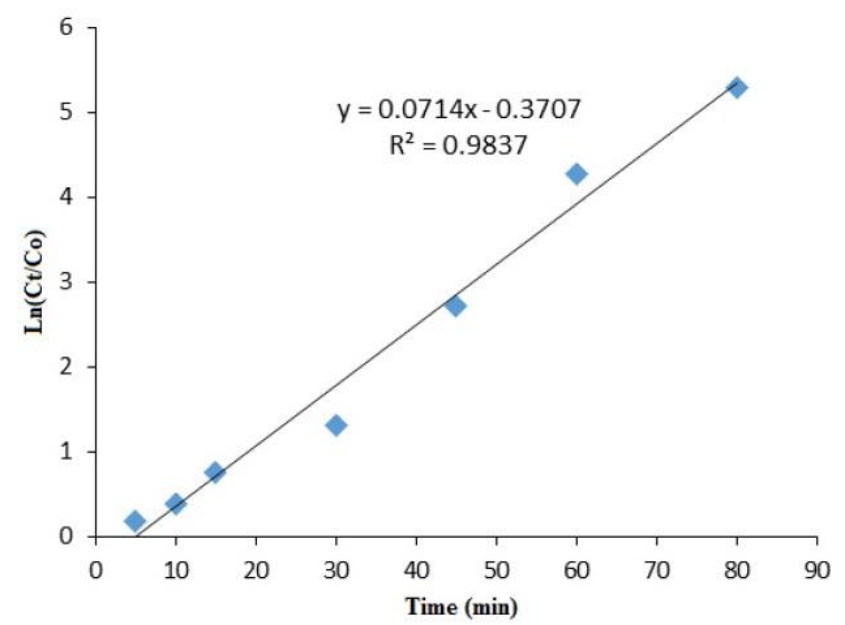

Figure 7. The effects of contact time on removal efficiency in optimum conditions $[\mathrm{pH}=7$, UV radiation $=30 \mathrm{~W}$, persulfate concentrations $(0.04 \mathrm{M})$, catechol concentration (100 $\left.\mathrm{mg} \mathrm{L}^{-1}\right)$.

\subsection{The simultaneous effects of variables}

The removal efficiency obtained in optimum conditions by each variable are illustrated in Figure 8 . The results showed removal efficiency of UV radiation and the sulfate radical radicals alone were $8.5 \%$ and $45 \%$, respectively. The results indicated that UV radiation was caused low degradation of catechol. Ghaderpoori et al. study (2016) showed that UV radiation alone was not useful to degrade the linear alkylbenzene sulfonate (LAS) (Ghaderpoori and Dehghani, 2016). Like UV radiation, the sulfate radical had little effect on catechol degradation (actually a little more of UV radiation alone). However, combination of UV radiation and the sulfate radical had removal efficiency of catechol about $88 \%$. In this stage, the sulfate radical produced, which was an effective factor in promotion of removal efficiency. In fact, the synergic effects were result from the presence of UV radiation (Safari et al., 2015). It enhances $\mathrm{UV} / \mathrm{S}_{2} \mathrm{O}_{8}{ }^{2-}$ and produces the sulfate radical which can be effective in degradation of organic matters. The previous studies in agreement to this study that the UV radiation was an activation important factor for persulfate radicals and the sulfate radical (Astereki et al., 2016; Liu and Li, 2006; Sun et al., 2011; Wang and Liang, 2014).

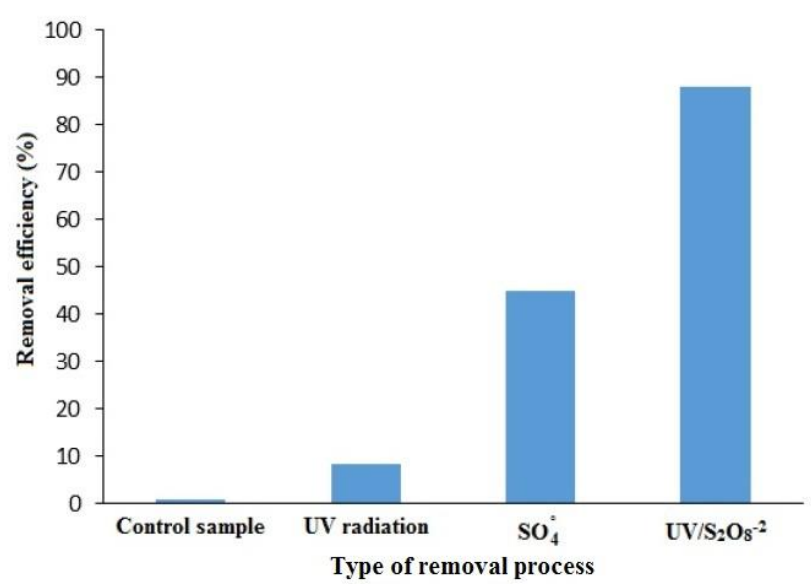

Figure 8. Removal efficiency of various processes in optimum conditions $[\mathrm{pH}=7, \mathrm{UV}$ radiation $=30 \mathrm{~W}$, persulfate concentrations $(0.04 \mathrm{M})$, catechol concentration (100 $\left.\mathrm{mg} \mathrm{L}^{-1}\right)$, and contact time $=60 \mathrm{~min}]$.

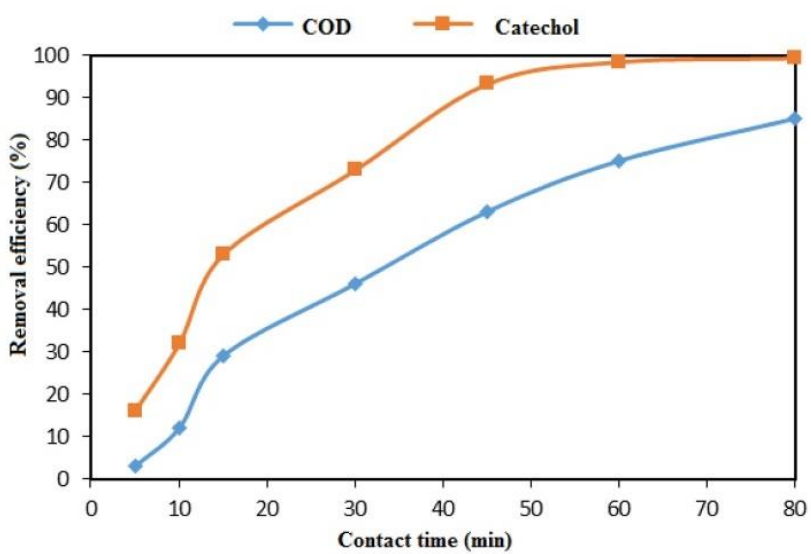

Figure 9. The removals efficiency of COD and catechol in optimum conditions $[\mathrm{pH}=7, \mathrm{UV}$ radiation $=30 \mathrm{~W}$, persulfate concentrations $(0.04 \mathrm{M})$, catechol concentration (100 $\left.\mathrm{mg} \mathrm{L}^{-1}\right]$.

\subsection{Mineralization of Catechol}

COD is an important indicator for complete degradation of organic matters. Figure 9 shows the removal efficiency of COD and catechol in optimum conditions. As can be seen in Figure 9, the removal efficiency trends of COD and catechol are the same. On the other hand, after $80 \mathrm{~min}$ the removals efficiency of catechol and COD were 99.6 and 85\%, respectively, which are agreement to Mousavi et al. (2014) obtained removals efficiency 98 and $74.4 \%$ for catechol and COD, respectively (Moussavi et al., 2014). The results showed UV/ $\mathrm{S}_{2} \mathrm{O}_{8}{ }^{2-}$ completely degraded catechol instead of slight degradation of target pollutant. The differences between two charts in Figure 9 demonstrate the production of by-products, which are created by 
degradation of catechol. Lin et.al concluded which this process can completely (100\%) remove phenol from aqueous solutions within 20 min (Fang and Shang, 2012). In another study conducted by Fang et.al, this process could remove 2-bromoacetamide completely from aquatic environments (He et al., 2013). Finally, the use of these processes before biological systems can decrease COD less than discharge standards for wastewater into environment.

\section{Conclusion}

In this study, we investigated the optimization of fluoride removal with UV/ $\mathrm{S}_{2} \mathrm{O}_{8}{ }^{2}$. To design experiments, Design of Experiments Software and CCD was applied. In order to determine removal efficiency of catechol, initial catechol concentrations, $\mathrm{pH}$, and persulfate radicals were considered. The results showed that the catechol removal by UV/S $\mathrm{S}_{2} \mathrm{O}_{8}^{-2}$ was fitted to polynomial models. Removal efficiency of catechol in the optimal conditions obtained $90 \%$. The best $\mathrm{pH}$ to remove the catechol was neutral conditions. The removal efficiency of catechol was reduced by almost $20 \%$ at acidic and alkaline $\mathrm{pH}$.

\section{Acknowledgement}

The study authors are grateful for financial support from Khorramabad University of Medical Sciences

\section{References}

Alinejad A., Akbari H., Ghaderpoori M., Jeihooni A.K. and Adibzadeh A. (2019), Catalytic ozonation process using a MgO nano-catalyst to degrade methotrexate from aqueous solutions and cytotoxicity studies in human lung epithelial cells (A549) after treatment, RSC Advances, 9, 8204-8214.

Antoniou M.G., Armah A. and Dionysiou D.D. (2010), Degradation of microcystin-LR using sulfate radicals generated through photolysis, thermolysis and e- transfer mechanisms, Applied Catalysis B: Environmental, 96, 290-298.

Astereki S., Kamarehie B. and Jafari A. (2016), 2-chlorophenol removal of aqueous solution using advanced oxidation processes resulting from iron/persulfate and ultra violet/persulfate, Iranian Journal of Toxicology, 10, 1-8.

Azarpira H., Sadani M., Abtahi M., Vaezi N., Rezaei S., Atafar Z., Mohseni S.M., Sarkhosh M., Ghaderpoori M. and Keramati H. (2019), Photo-catalytic degradation of triclosan with UV/iodide/ZnO process: Performance, kinetic, degradation pathway, energy consumption and toxicology, Journal of Photochemistry and Photobiology A: Chemistry, 371, 423432.

Azbar N., Yonar T. and Kestioglu K. (2004), Comparison of various advanced oxidation processes and chemical treatment methods for COD and color removal from a polyester and acetate fiber dyeing effluent, Chemosphere, 55, 35-43.

Bayram E., Hoda N. and Ayranci E. (2009), Adsorption/electrosorption of catechol and resorcinol onto high area activated carbon cloth, Journal of Hazardous Materials, 168, 1459-1466.

Boukari S.O., Pellizzari F. and Leitner N.K.V. (2011), Influence of persulfate ions on the removal of phenol in aqueous solution using electron beam irradiation, Journal of Hazardous Materials, 185, 844-851.
Chu W., Li D., Gao N., Templeton M.R., Tan C. and Gao Y. (2015), The control of emerging haloacetamide DBP precursors with UV/persulfate treatment, Water Research, 72, 340-348.

Eaton A.D., Clesceri L.S. and Rice E.W. (2005). Standard Methods for the xamination of Water and Wastewater (PAHA). American Water Works Association, Washington DC, USA.

Esrafili A., Rezaei Kalantary R., Azari A., Ahmadi E. and Gholami M. (2016), Removal of diethyl phthalate from aqueous solution using persulfate-based $\left(\mathrm{UV} / \mathrm{Na}_{2} \mathrm{~S}_{2} \mathrm{O}_{8} / \mathrm{Fe}^{2+}\right)$ advanced oxidation process, Journal of Mazandaran University of Medical Sciences, 25, 122-135.

Fang J.-Y.and Shang C. (2012), Bromate formation from bromide oxidation by the UV/persulfate process, Environmental Science \& Technology, 46, 8976-8983.

Gao Y.Q., Gao N.Y., Deng Y., Yang Y.Q. and Ma Y. (2012), Ultraviolet (UV) light-activated persulfate oxidation of sulfamethazine in water, Chemical Engineering Journal, 195, 248-253.

Gayathri P., Dorathi R.P.J. and Palanivelu K. (2010), Sonochemical degradation of textile dyes in aqueous solution using sulphate radicals activated by immobilized cobalt ions, Ultrasonics Sonochemistry, 17, 566-571.

Ghaderpoori M. and Dehghani M.H. (2016), Investigating the removal of linear alkyl benzene sulfonate from aqueous solution by ultraviolet irradiation and hydrogen peroxide process, Desalination and Water Treatment, 57, 1520815212.

Golmohammadi S., Ahmadpour M., Mohammadi A., Alinejad A., Mirzaei N., Ghaderpoori M. and Ghaderpoori A. (2016), Removal of blue cat 41 dye from aqueous solutions with $\mathrm{ZnO}$ nanoparticles in combination with US and US- $\mathrm{H}_{2} \mathrm{O}_{2}$ advanced oxidation processes, Environmental Health Engineering and Management Journal, 3, 107-113.

Guo Y., Zhou J., Lou X., Liu R., Xiao D., Fang C., Wang Z. and Liu J. (2014), Enhanced degradation of Tetrabromobisphenol $A$ in water by a UV/base/persulfate system: Kinetics and intermediates, Chemical Engineering Journal, 254, 538-544.

Haidari S., Kamarehie B., Jafari A., Birjandi M. and Afrasyabi S. (2016), Oxalic acid degradation from aqueous solution using ozonation process in the presence of magnesium oxide nanoparticles catalyst stabilized on activated carbon, International Journal of Environmental Health Engineering, 5, 23.

Hasanpour M. and Hatami M. (2020a), Application of three dimensional porous aerogels as adsorbent for removal of heavy metal ions from water/wastewater: A review study, Advances in Colloid and Interface Science, 284, 102247.

Hasanpour M. and Hatami M. (2020b), Photocatalytic performance of aerogels for organic dyes removal from wastewaters: Review study, Journal of Molecular Liquids, 309, 113094.

He X., Armah A. and Dionysiou D.D. (2013), Destruction of cyanobacterial toxin cylindrospermopsin by hydroxyl radicals and sulfate radicals using UV-254nm activation of hydrogen peroxide, persulfate and peroxymonosulfate, Journal of Photochemistry and Photobiology A: Chemistry, 251, 160166.

Kamali H. and Ghaziaskar H. (2010), Pressurized hot water extraction of benzoic acid and phthalic anhydride from petrochemical wastes using a modified supercritical fluid 
extractor and a central composite design for optimization, The Journal of Supercritical Fluids, 54, 16-21.

Kamarehie B., Jafari A., Ghaderpoori M., Amin Karami M., Mousavi K. and Ghaderpoury A. (2019), Catalytic ozonation process using PAC/ $\mathrm{Y}-\mathrm{Fe} 2 \mathrm{O} 3$ to Alizarin Red S degradation from aqueous solutions: a batch study, Chemical Engineering Communications, 206, 898-908.

Kamarehie B., Tizabi S.M.S., Heydari R., Jafari A., Ghaderpoori M., Karami M.A. and Ghaderpoury A. (2018), Data on the bisphenol $A$ adsorption from aqueous solutions on PAC and MgO PAC crystals, Data in Brief, 21, 746-752.

Kamarehie B., Tizabi S.M.S., Heydari R., Sadeghi S., Ghaderpoori M., Ghaderpoury A. and Alinejad A. (2020), Catalytic ozonation process using MgO-PAC to degrade bisphenol A from aqueous solutions, Desalination and Water Treatment, 184, 232-242.

Karimi B., Rajaei M., Habibi M., Esvand M., Abdollahy M. (2013), Effect of $\mathrm{UV} / \mathrm{H}_{2} \mathrm{O}_{2}$ advanced oxidation processes for the removal of naphthalene from the water solution, Journal of Arak University of Medical Sciences, 16, 50-64

Khataee A. (2009), Application of central composite design for the optimization of photo-destruction of a textile dye using $\mathrm{UV} / \mathrm{S}_{2} \mathrm{O}_{8}$-process, Polish Journal of Chemical Technology, 11, $38-45$.

Lee Y.C., Lo S.L., Chiueh P.T. and Chang D.G. (2009), Efficient decomposition of perfluorocarboxylic acids in aqueous solution using microwave-induced persulfate, Water Research, 43, 2811-2816.

Liang C., Wang Z.S. and Mohanty N. (2006), Influences of carbonate and chloride ions on persulfate oxidation of trichloroethylene at $20 \mathrm{C}$, Science of the Total Environment, 370, 271-277.

Lin C.C., Lee L.T. and Hsu L.J. (2013), Performance of UV/S 208 2- process in degrading polyvinyl alcohol in aqueous solutions, Journal of Photochemistry and Photobiology A: Chemistry, 252, 1-7.

Lin Y.T., Liang C.and Chen J.H. (2011), Feasibility study of ultraviolet activated persulfate oxidation of phenol, Chemosphere, 82, 1168-1172.

Liu C.C., Li Y.S. (2006), Decoloration of reactive Black 5 in aqueous solution by electro-Fenton reaction, Journal of Environmental Engineering and Management, 16, 243-248

Liu Y., Gao M., Gu Z., Luo Z., Ye Y. and Lu L. (2014), Comparison between the removal of phenol and catechol by modified montmorillonite with two novel hydroxyl-containing Gemini surfactants, Journal of Hazardous Materials, 267, 71-80.

Lofrano G., Rizzo L., Grassi M. and Belgiorno V. (2009), Advanced oxidation of catechol: A comparison among photocatalysis, Fenton and photo-Fenton processes, Desalination, 249, 878883.

Massoudinejad M., Ghaderpoori M., Shahsavani A. and Amini M.M. (2016), Adsorption of fluoride over a metal organic framework Uio-66 functionalized with amine groups and optimization with response surface methodology, Journal of Molecular Liquids, 221, 279-286.

Massoudinejad M., Keramati H. and Ghaderpoori M. (2020), Investigation of photo-catalytic removal of arsenic from aqueous solutions using $\mathrm{UV} / \mathrm{H}_{2} \mathrm{O}_{2}$ in the presence of $\mathrm{ZnO}$ nanoparticles, Chemical Engineering Communications, 207, 1605-1615.
Massoudinejad M., Shahsavani A., Kamarehie B., Jafari A., Ghaderpoori M., Amini M.M. and Ghaderpoury A. (2018), Highly efficient adsorption of fluoride from aqueous solutions by metal organic frameworks: Modeling, isotherms, and kinetics, Fluoride, 51, 355-365.

Moussavi G., Aghapour A.A. and Yaghmaeian K. (2014), The degradation and mineralization of catechol using ozonation catalyzed with $\mathrm{MgO} / \mathrm{GAC}$ composite in a fluidized bed reactor, Chemical Engineering Journal, 249, 302-310.

Olmez-Hanci T. and Arslan-Alaton I. (2013), Comparison of sulfate and hydroxyl radical based advanced oxidation of phenol, Chemical Engineering Journal, 224, 10-16.

Peternel I., Grcic I. and Koprivanac N. (2010), Degradation of reactive azo dye by UV/peroxodisulfate system: an experimental design approach, Reaction Kinetics, Mechanisms and Catalysis, 100, 33-44.

Rasoulifard M.H., Doust M.S.M.M. and Heydari A. (2012), Removal of acid red 14 from contaminated water using uv/s2o82-advanced oxidation process, Water And Wastewater, 26, 22-31

Rokhina E.V., Repo E. and Virkutyte J. (2010), Comparative kinetic analysis of silent and ultrasound-assisted catalytic wet peroxide oxidation of phenol, Ultrasonics Sonochemistry, 17, 541-546.

Safari G.H., Nasseri S., Mahvi A.H., Yaghmaeian K., Nabizadeh R. and Alimohammadi M. (2015), Optimization of sonochemical degradation of tetracycline in aqueous solution using sonoactivated persulfate process, Journal of Environmental Health Science and Engineering, 13, 76.

Salari D., Daneshvar N., Niaei A., Aber S. and Rasoulifard M. (2008), The photo-oxidative destruction of $\mathrm{Cl}$ Basic Yellow 2 using UV/S2O8 2- process in an annular photoreactor, Journal of Environmental Science and Health, Part A, 43, 657-663.

Shakir K., Ghoneimy H., Elkafrawy A., Beheir S.G. and Refaat M. (2008), Removal of catechol from aqueous solutions by adsorption onto organophilic-bentonite, Journal of Hazardous Materials, 150, 765-773.

Shiying Y., Ping W., Xin Y., Guang W., Zhang W. and Liang S. (2009), A novel advanced oxidation process to degrade organic pollutants in wastewater: Microwave-activated persulfate oxidation, Journal of Environmental Sciences, 21, 1175-1180.

Shokouhi R., Ebrahimzadeh L., Rahmani A.R., Ebrahimi S. and Samarghandi M.R. (2009), Comparison of the advanced oxidation processes in phenol degradation in laboratory scale, Water and Wastewater, 4, 30-35

Shukla P., Fatimah I., Wang S., Ang H. and Tadé M.O. (2010a), Photocatalytic generation of sulphate and hydroxyl radicals using zinc oxide under low-power UV to oxidise phenolic contaminants in wastewater, Catalysis Today, 157, 410-414.

Shukla P., Wang S., Singh K., Ang H. and Tadé M.O. (2010b), Cobalt exchanged zeolites for heterogeneous catalytic oxidation of phenol in the presence of peroxymonosulphate, Applied Catalysis B: Environmental, 99, 163-169.

Shukla P.R., Wang S., Sun H., Ang H.M. and Tadé M. (2010c), Activated carbon supported cobalt catalysts for advanced oxidation of organic contaminants in aqueous solution, Applied Catalysis B: Environmental, 100, 529-534.

Sun H., Feng X., Wang S., Ang H.M. and Tadé M.O. (2011), Combination of adsorption, photochemical and photocatalytic degradation of phenol solution over supported zinc 
oxide: Effects of support and sulphate oxidant, Chemical Engineering Journal, 170, 270-277.

Sun H., Wang S., Ang H.M., Tadé M.O. and Li Q. (2010), Halogen element modified titanium dioxide for visible light photocatalysis, Chemical Engineering Journal, 162, 437-447.

Wang C.-W. and Liang C. (2014), Oxidative degradation of TMAH solution with UV persulfate activation, Chemical Engineering Journal, 254, 472-478.

Xu X., Li S., Hao Q., Liu J., Yu Y. and Li H. (2012), Activation of persulfate and its environmental application, International Journal of Environment Bioenergy, 1, 60-81.

Yazdanbakhsh A., Hashempour Y. and Ghaderpouri M. (2018), Performance of granular activated carbon/nanoscale zerovalent iron for removal of humic substances from aqueous solution based on experimental design and response surface modeling, Global Nest Journal, 20, 57-68.

Yoon S.-H., Jeong S. and Lee S. (2012), Oxidation of bisphenol A by $\mathrm{UV} / \mathrm{S}_{2} \mathrm{O}$ : Comparison with $\mathrm{UV} / \mathrm{H}_{2} \mathrm{O}_{2}$, Environmental Technology, 33, 123-128.

Zarrabi M., Rahmani A.R., Samarghandi M.R. and Barjasteh Askary F. (2013), Investigation the zero-valent iron (ZVI) performance in the presence of uv light and hydrogen peroxide on removal of azo dyes acid orange 7 and reactive black 5 from aquatic solutions, Iranian Journal of Health and Environment, 5, 469478.

Zhao J., Zhang Y., Quan X. and Chen S. (2010), Enhanced oxidation of 4-chlorophenol using sulfate radicals generated from zerovalent iron and peroxydisulfate at ambient temperature, Separation and Purification Technology, 71, 302-307. 